Başvuru: 29 Ağustos 2020 Düzeltme: 10 Kasım 2020 Kabul: 25 Aralık 2020

\title{
https://doi.org/10.46291/ISPECIJSSHvol4iss5pp535-551
}

\section{Eleştirel Jeopolitik Çerçevesinde 1971-2006 Yıllarında Bangladeş’in Dış Politika Çalışmalarının Analizi}

\section{Rahmat Ullah}

Doktora Adayı, Uluslararası İlişkiler Bölümü, Karadeniz Teknik Üniversitesi, rafiq35ju@gmail.com

ORCID:0000-0002-1548-5966

\section{Özet:}

1980'lı yıllarında 'klasik jeopolitik teorisi'ni eleştirerek uluslararası ilişkiler analizinde yeni bir yaklaşım olarak (olan) 'eleştirel jeopolitik' kavramı ortaya çıkmıştır. Devletin farklı birim ve kuruluşlarının dış politika çalışmalarına odaklanarak bir ülkenin uluslararası alanındaki konumunu araştıran bu kavram daha sonra 'jeopolitik' çalışmalarında çok ilgi toplamıştır. Bu çalışmada, Bangladeş'in kuruluşundan 2006 yılına kadar dış politika çalışmaları 'eleştirel jeopolitik' açısından analiz edilmiş ve uluslararası ve bölgesel kuruluşlarda oynadığı roller değerlendirilmiştir. Çalışmada, soğuk savaşı döneminde ABD ve Çin'in müttefiki olan ve Güney Asya'nın en büyük Müslüman ülkesi olan Pakistan'a karşı savaşının ardından bağımsızlığını kazanan Bangladeş’in ilk yıllarındaki dış politika çalışmalarının çok başarılı olduğu görülmüştür. Özellikle uluslararası kuruluşların çok kısa bir süre içinde üyeliğinin kazanılması, Pakistan, Çin ve ABD ve Müslüman ülkelerle çok hızlı bir şekilde ikili ilişkilerin geliştirmesi ve bölgesel iş birliği çalışmaları fikrini ortaya koyması ve dünya barışının korunması çalışmalarını teşvik etmesi Bangladeş'in jeopolitik konumunu güçlendirmesini kolaylaştırmıştır. Uluslararası alandaki aktif rolü dolaysıyla Bangladeş`in kendi ekonomik çıkarlarını da elde ettiği görülmüştür.

Anahtar Kelimeler: Eleştirel Jeopolitik, Bangladeş, Dış Politika Çalışmaları, 1971-2006 Dönemi 


\title{
The Analysis of Bangladesh's Foreign Policy Activities in 1971-2006 in terms of Critical Geopolitics
}

\begin{abstract}
:
In the 1980s, the concept of 'critical geopolitics' emerged as a new approach in international relations analysis by criticizing the 'classical geopolitical theory'. This concept, which investigates the position of a country in the international arena by focusing on the foreign policy activities of different units and organizations of a country, has attracted a lot of attention in 'geopolitics' studies. In this study, foreign policy activities and the roles of Bangladesh in international and regional organizations between 1971 to 2006 were analyzed in terms of 'critical geopolitics'. In the study, it was seen that Bangladesh, which gained its independence after the war against Pakistan, which was an ally of the USA and China during the cold war and which was the biggest Muslim country in South Asia, was very successful in its foreign policy activities in the first years. Especially, gaining membership in international organizations in a very short time, developing bilateral relations with Pakistan, China and the USA and Muslim countries very quickly, and putting forward the idea of regional cooperation efforts and promoting efforts to protect world peace have facilitated the strengthening of Bangladesh's geopolitical position. Due to its active role in the international arena, Bangladesh has been seen to have its own economic interests. Due to its active role in the international arena, Bangladesh also gained its own economic interests.
\end{abstract}

Keywords: Critical Geopolitics, Bangladesh, Foreign Policy Activities, 1971-2006 Period

\section{Giriş}

1971 yılında bağımsızlığını kazanan Bangladeş Halk Cumhuriyeti yüz ölçümü açısından çok küçük olup bölgenin en kalabalık ülkelerinden biri olarak Güney Asya haritasında yerini almıştır. Ancak, Pakistan ordusu ile yaklaşık 9 aylık savaş sonucunda alt yapı, sosyal ve ekonomik alanında büyük hasarlarıyla beraber ülke olarak ortaya çıkan Bangladeş'in ilk yılları çok zor geçmiştir. Çünkü, soğuk savaşı sırasında Pakistan ordusuna karşı savaşan Bangladeş yetkilileri Çin ve ABD’ye karşılarında bulmuştur. Ayrıca, Müslüman ülkeleri de Bangladeş halkına destek vermemiş ve Pakistan'ın yanında yer almıştır. Öte yandan, Pakistan'ın iki bölgesi arasında patlak veren savaşı Pakistan'ın bölünmesinin bir fırsatı olarak değerlendiren Hindistan, Bangladeşli siyasi yetkililere ve savaşçılara gereken destek 
sağlayarak Bangladeş'in bağımsızlığını hızlandırmış ve kendi yetki altında tutmayı hedeflemiştir. Coğrafi konumu olarak Doğu, Batı ve Kuzey taraftan Hindistan çevrili olması, Bangladeş üzerinde Hindistan'ın etkisi olacağı endişelerini daha da güçlendirmiştir. Böyle bir durumda Hindistan'ın etkisi altından çıkarak dünya ülkeleriyle ilişki kurmak ve uluslararası kuruluşlara üye olup ülkenin geliştirilmesi konusunda gereken imkanları elde etmek için Bangladeş yetkilileri zor şartları altında diplomatik çalışmaları sürdürmüş ve kısa bir süre içinde ABD, Çin, Pakistan, Batılı ülkeler ve özellikle Müslüman ülkeleriyle ilişkiler kurarak uluslararası alanında aktif katılım sergilemiştir. Bu bağlamda Bangladeş'in ilk yıllarının dış politika çalışmalarını uluslararası ilişkilerin "eleştirel jeopolitik" kavramı çerçevesinde analiz etmek, ülkenin uluslararası alanındaki konumunu açıklayacağı gibi coğrafi konumunun zorluklarına rağmen kendi çıkarlarını nasıl sağlayabildiğini ortaya koyacaktır.

\section{Eleștirel Jeopolitik Kavramı}

Geçen yüzyılında devletçi, Avrupa merkezli, güç dengesi anlayışı temelinde kurulan klasik jeopolitik Dünya siyaseti analizinde hâkim olmuştur. Avrupa milliyetçiliğini ve emperyalizmini temel alarak ortaya çıkan klasik jeopolitik, baştan beri Avrupa devletlerinin rekabetçi hedefleriyle yakından bağlantılı olmuştur. Örneğin, Friedrich Ratzel'in "yaşam alanı" düşünceleri, Almanya'nın Avrupa siyasetindeki konumu konusundaki yaygın endişesinden kaynaklanmıştır. Öte yandan Halford Mackinder'in "heartland" veya "kalp bölgesi” teorisi İngiltere'deki benzer kaygıları yansıtmıştır (Tuathail, 1996). Klasik jeopolitik devletlerin ve ulusların doğal olarak yeni bölge ve kaynakları için rekabete ve savaşa sürüklemiştir. Klasik jeopolitiğin bu düşünceleri ve olumsuz etkilere eleştirerek 1980'li yıllarda uluslararası ilişkilerin analizinde yeni bir yaklaşım geliştirmiş̧ir. 'Eleştirel Jeopolitik' olarak tanımlanan bu yaklaşım jeopolitiğin toplumsal, kültürel ve siyasal bir söylem olduğunu savunmaktadır. Eleştirel yaklaşım bir ülkenin coğrafi konumu ve bu konumu dolaysıyla uluslararası ilişkilerde o ülkenin önemini değil, bir ülkenin uluslararası alanında oynadığı rol ve izlediği politika dolaysıyla kazandığı önemini araşıırmaktadır.

Eleştirel jeopolitik düşünürler bir ülkenin çeşitli kurumların diğer ülke ve bölgelerle yapılan politika, iş birliği, çalışmaları ve şekillerine dayanmaktadır. Eleştirel jeopolitik düşünürlere göre, bir ülkenin kimliği ile dış politikası belirlenmez ancak dış politika çalışmalarıyla bir ülkenin kimliği anlaşıllır-belirlenir (Kuus, 2010: 6). Dalby (1991: 274) eleştirel jeopolitiğini bir siyasetin (bir devletin) coğrafyasını araştırmak değil bir "siyasetin (devletin) coğrafi 
özelliklerinin siyaseti” araştırmak olarak tanımlanmıştır. Bu kavramının öne gelen Tuathail'e göre (1999: 109) eleştirel jeopolitik teorisyenler küreselleşmenin dinamikleri, bilgilendirme teknolojilerin yaygınlık, kararsızlık, çokluk, eşzamanlılık, karamsarlık, belirsizlik, biçimsizlik ve sınırsızlığını dikkate almaktadır. Tuathail jeopolitiğinin çok anlamlı olduğunu vurgulamaktadır. Tuathail eleştirel jeopolitiğin dört faklı jeopolitik türü olduğunu ileri sürmektedir: Fromel Jeopolitik, Pratik Jeopolitik, Popüler Jeopolitik ve Yapısal Jeopolitik.

Formel jeopolitik 'jeopolitik gelenek' ve 'jeopolitik düşünce'. Bir ülkenin bilim insanları, akademisyenler ve düşünce kuruluşlar tarafindan jeopolitik düşünceyi siyasi ve kültüre bağlamında şekillendirilmesidir. Örneğin: MacKinder veya Ratzel'in jeopolitik teorileri ve emperyalist bağlamı.

Pratik jeopolitik ise hükümet temsilcileri ve dış politika bürokratları tarafından konulan ve resmi dış siyasetlerinde ifadesini bulan günlük jeopolitik muhakeme biçimlerdir (Yeşiltaş, 2016: 359-60). Pratik jeopolitik ortak coğrafi anlayışların ve algıların dış politika kavramsallaştırmasını ve karar vermeyi nasıl etkilediğini ele almaktadır. Örneğin, "Balkanlar" coğrafi kavramı ABD dış politika yapıcılarının Bosna Savaşı'na nasıl yaklaşı̆ı̆ını, kavramsallaştırdığını ve yanıt verdiğini ortaya koymuştur.

Popüler jeopolitik medyayı şekillendiren popüler kültürün yarattığı ve tartıştığı coğrafi politikaları ifade etmektedir. Popüler jeopolitik kendi sınırlarının ötesindeki yer ve halkların bazı ulusal ve ulus ötesi anlayışların sosyal inşasını ve sürekliliğini ele almaktadır. Örneğin, Bosna savaşını görüntülerinin Batı'daki oturma odalarına yansıtılmasında kitle iletişim araçlarının rolü.

Yapısal jeopolitik ise uluslararası alanında ülkelerin dış politika süreçleri, eğilimleri ve koşulları okumaktır. Yapısal jeopolitik küresel süreçler, eğilimler ve çelişkilere incelemektir. Küreselleşme, bilgilini kolaylaşma ve risk toplumu koşullarının jeopolitik uygulamaları nasıı dönüştürdüğü ile ilgilidir (Tuathail, 1999: 110-11).

Dolaysıyla, eleştirel jeopolitik uluslararası ilişkilerde ülkelerin rollerinin analizinde iktidar, siyasi ve toplumsal kültürü, bilgi oluşumları, kurumların etkileri gibi çeşitli açılardan değerlendirmeye yönelik yeni bir kavram olarak kullanılmaktadır.

\section{1971-2006 Yıllarında Uluslararası Alanında Bangladeş'in Rolü}

Coğrafi zorluklarını aşmak, ekonomik çıkarlarını elde etmek ve kendi güvenliğini korumak amacıyla bağımsızlığın hemen ardından Bangladeş uluslararası ortamlarda aktif dış politika 
izlemeye başlamıştır. Uluslararası sisteminde barışçıl politikası izleyerek bölgesel ve dünya kuruluşlarında kendi konumunu belli etmeye çalışmıştır. Uluslararası alanında ortak çalışmalar ve iş birliğini savunarak hem kendi çıkarlarını elde etmiş hem de uluslararası krizlerin çözümüne katkılarda bulunmuştur.

\subsection{Birleşmiş Milletler’indeki Rolü}

Bangladeş 1974 yılının 17 Eylül tarihinde BM'nin 136. üyesi olmuştur. Bağımsızlığından yaklaşık üç yıl sonra BM'nin tam üyeliğini kazanan Bangladeş diğer BM organlarının üyeliğini daha da önce almıştır. BM üyesi olarak 1974'ten itibaren Bangladeş BM'nin politik, güvenlik, ekonomik ve sosyal çalışmalarında önemli ve aktif rol oynamış ve dünya barışı için kendi çabasını göstermiş̧tir. Üyeliğinin bir yıl sonra 1975'te Genel Kurulda Başkan Yardımcısı seçilmiştir. 1976-1978, 1981-1983 (Bdnews24.com, 2013) yılında Ekonomik ve Sosyal Konsey (ECOSOC) üyesi olarak seçilmiş ve görev yapmıştır. Bangladeş temsilcisi Humayun Rasheed Chowdhury, 1986-87 y1llarında BM Genel Kurulu'nun 41. oturumunun başkanlığ1 yapmıştır. BM'nin Güvenlik Konseyi'nde 1979-1980 ve 2000-2001 yıllarında daimî olmayan üyesi olarak seçilmiş ve uluslararası sorunların barışçıl bir çözümüne önemli katkıda bulunmuştur. 1979-1980 döneminde Arap-İsrail sorunu, Vietnam'ın Kamboçya işgali, Afganistan'da Sovyet işgali, İran-Irak savaşı, İran'da rehin sorunu ve Güney Afrika'dan Rodezya (Zimbabve)'nın bağımsızlığı ve Güney Afrika'ya silah ambargosu gibi dünya gündemde olan önemli sorunların barış̧̧ıl çözümüne aktif rol oynamıştır. Özellikle işgal altındaki Arap topraklarından Yahudi yerleşimlerinin boşaltması ve İran-Irak savaşını durdurma çabasının içinde yer alıp önemli rol oynamıştır. Bu iki yıllık döneminde İsrail'in işgal karşı güçlü sesini yükseltmeyi başarmıştır (Momen, 2004: 125-39).

Bangladeş'in Müslüman ülkelere ile olan bağı özellikle Filistin toprağına olan saygı; diplomasında takip ettiği ılımlı ilkesi ve Bağlantısızlar Örgütü (NAM) ve İslam İş birliği Teşkilatı (OIC) üyelerin desteği ile Bangladeş BM güvenlik konseyinde çok etkili olmuştur (Momen, 2004: 125-39). Tahran'da rehin tutulan Amerikan diplomatlarının serbest bırakılması konusunda barış̧̧1 bir çözümü için gayret göstermiştir (Huq, 1993: 312-18). Aynı dönemde, Bangladeş, Zimbabve olarak bağımsızlığını kazanan Rodezya'daki seçimleri BM adına denetmiştir ve BM Güvenlik Konseyi'nin Güney Afrika'daki Silah Ambargo Komitesinin başkanlığını yapmıştır. BM Güvenlik konseyinde 2000-2001 döneminde üyesi seçilen Bangladeş önemli bir rol oynamıştır. Bu dönemin gündemi olan Angola, Bosna 
Hersek, Demokratik Kongo Cumhuriyeti (DRC), Irak, Kosova, Sierra Leone ve Doğu Timor konularda barışçıl konumunu savunmuştur. Bangladeş bu döneminde Sierra Leone ve Yaptırımların Rolüne İlişkin Çalışma Komitesi'ne başkanlığını yapmıştır. Bangladeş ayrıca 2000 yılının mart ayında ve haziran 2001'de Güvenlik Konseyi başkanlığını da yapmıştır (Hossain, 2014). İnsan Haklarını ön plana koyan Bangladeş BM'de insan hakları konusunda önemi rol oynamıştır. Bangladeş’in eski Başkanı Abu Sayeed Chowdhury 1985 yılında İnsan Hakları Komisyonu (CHR)'na başkanlık yapmıştır. Bangladeş 1983-2000 yılları arasında İnsan Hakları Komisyonu üyesi olarak görev yapmış.

Uluslararası ortamlarda gelişmekte olan ve az gelişmiş ülkelerin çıkarlarının artması gerektiğini savunan Bangladeş, 1982-83 yıllarında 77 Grubun başkanlığı yapmıştır. Ayrıca, 1980'den bu yana En Az Gelişmiş Ülkelerin koordinatörü olarak BM faaliyetlerine katkıda bulunmuştur. Bağımsızlığı için yaklaşık 9 aylık savaşa maruz kalan Bangladeş halkı dünya ülkelerinin barış içinde yaşamasını önemsemiştir. Bu yüzden BM üyeliğin ilk günden beri silahsızlanma konusunda Bangladeş konumunu belirlediği gibi ülkelerin bir araya gelmesinin gerektiğini de önemsemiştir. BM Genel Konseyinde ilk Bangladeşli olarak konuşma yaparken dönemin Bangladeş Başkanı Şeyh Mujibur Rahman da dünya ekonomik sorunların çözümüne barış ortamının önemini ve silahsızlanmanın gerektiğini ortaya koymuştur. Sonraki dönemlerde de Bangladeşli temsilciler aynı duruşunu göstermişlerdir (Huq, 1993: 299-302). Ayrıca savaş veya çatışma çıkan ülkelerini barışa kavuşturmak için Bangladeş, 1988 yılından beri BM Barış Gücü Misyonunda aktif rol oynamaktadır.

\subsection{Birleşmiş Milletler Barış Gücü’ne Bangladeş'in Rolü}

1988 yılında İran-Irak Askeri Gözlem Grubu'na (UNIMOG) 15 askeri gözlemci ile katılan Bangladeş dünya çapında çatışma bölgelerinde barışı inşa etmek ve korumak için BM Barış Gücü'ne asker, polis ve sivil personel gönderen ülkeler arasında ilk sırada yer alan ülkeler arasındadır. Dış politikasında 'barış’ ilkesini takip eden Bangladeş BM Barış Gücü çerçevesinde savaş ve iç çatışmaya maruz kalan ülkelerin barışı koruma ve barışa giden zorlu yolda ilerlemesine ülkelere yardımcı olma gibi görevler yapmıştır. Bunların yanı sıra insanların emniyetinin sağlanması, ihtilaflı taraflar arasında itimat artırıcı önlemler alınması, seçimlerin yapılmasına katkıda bulunulması, yol ve diğer yapısal projelerin yapılması, sağlık ve eğitim hizmetler verilmesi gibi farklı çalışmalar yapmıştır. Bu çalışmalarıyla Bangladeş hem sorunlu ülke ve bölgelerinin barışa ve kalkınmasına yardımcı olmuş hem de uluslararası

Year 4/ 2020, Volume-4, Issue-5 | WwW.ispecjournal.org 
ekonomi ve siyasetine büyük fırsatları sağlamıştır. Ayrıca, sorunlu ülkelerine barış götürerek hem büyük miktarda ekonomik geliri elde etmiş hem de uluslararası ortamda kendi olumlu imajını oluşturmuştur. Bunlarla birlikte hizmet verdiği sorunlu ülkelerin halk ve yönetim ile iyi ve kalıcı bir ilişki kurabilmiştir. Ayrıca, ikili ticaret ve iş imkânlarını da artırmıştır. Bangladeş ayrıca bu hizmetleriyle ekonomisine dış yardım, uluslararası yatırım ve uluslararası diğer destek çekmeyi de başarmıştır. 1988'den 2006 yılına kadar Birleşmiş Milletler Barış Gücüne katılan 100'e yakın görevli hayatlarını kaybetmiştir (Peacekeeping.un.org, t.y.). Fakat bu fedakârlıklar Bangladeş için bazı onuru da getirmiştir. Sierra Leone Bengalceyi resmi bir dil olarak tanımış ve bir bulvarını Bangladeş olarak adlandırmıştır (Rabbi, 2017).

\subsection{Bağlantısızlar Hareketi'nde Bangladeş}

Bangladeş 1973 yılında Bağlantısızlar Hareketi'nin üyesi olmuştur (Huq, 1993: 64). Çatışmanın yerine ortak kazancını politika olarak belirleyen Bangladeş ilk dönemlerden beri Bağlantısızlar Hareketi çerçevesinde gelişmekte olan ülkelerin ekonomik ve siyasi çıkarları konusunda aktif olarak kendi görüşlerini ortaya koymuş ve Asya, Amerika ve Afrika ülkeleriyle bir araya gelerek dinamik bir siyaseti izlemiştir (Ahamed, 2004: 49-50). Büyük ülkelerin silahlanma yarışına karşı BM ve NAM üyesi gelişmekte olan ülkeleriyle bir araya gelip etkili rol oynamıştır. Ayrıca, BM'de Yeni Uluslararası Ekonomik Düzen (NIEO), Ortadoğu krizi, Güney Afrika'dan ırkçılığın ortadan kaldırılması gibi önemli konularda etkili rol oynayan NAM ülkeler arasında Bangladeş de bulunmuştur. 1979 yılında NAM zirvesinde üye ülkelerin gıda ihtiyaçlarını karşılamak için ortak “Gıda Güvenlik Sistemi”nin oluşturmasına teklif etmiştir. Ayrıca NAM ülkelerin “İnsan Kaynakları Gelişimi” için de ayrı bir çalışma olmasını ve bir kurumun gerektiğini ortaya koymuştur. Bangladeş'in ortaya koyduğu bu görüşler NAM üyeler arasında büyük ilgi kazanmış ve NAM çerçevesinde "İnsan Kaynakları Gelişimi Okumaları” kuruluşunda Bangladeş’i koordinatör görevini verilmiştir (Huq, 1993: 64).

\subsection{Grubu ve Bangladeş}

Yeni Uluslararası Ekonomik Düzen (NIEO) çalışmalarında az gelişmiş ülkelerin ekonomik ihtiyaçlarını duyuran ve bu konuda ses getirmeye çalışan Bangladeş’in çabalarıyla 77 Gurubu'nda bir alt grubu oluşmuştur. $\mathrm{Bu}$ alt grubunun çalışması $\mathrm{BM}$ ve NIEO'nun 
politikalarını etkilemiş ve sanayi ülkeleri karşısında az gelişmekte olan ülkelerin taleplerini dile getirmiş ve ekonomik imkânlarını artırmıştır.

\section{5 İslam İş Birliği Teşkilatının Üyeliği ve Rolü}

Pakistan ile savaşarak bağımsızlığını kazanan Bangladeş ilk yıllarda Müslüman ülkeler ile diplomatik ilişkileri kurulmasında sorunlar yaşamıştır. Ancak, Halkın \%88’i Müslüman olan ve Müslüman ülkeleriyle kardeşlik ilkesini anayasasında yer veren Bangladeş kuruluşunun ardından Müslüman ülkeleriyle ilişkileri kurmak amacıyla farklı diplomatik çalışmaları başlatmıştır. 22 Şubat 1974 tarihinde Pakistan Bangladeş' in bağımsızlığını tanımıştır ve aynı gün Müslüman ülkeler arasında ektili ülkeleri olan Türkiye ve İran da Bangladeş’i resmi olarak tanımış. Bu gelişmelerin hemen ardından Müslüman ülkeleriyle kardeşlik ilişkilerini ilan etmesi için Bangladeş başbakanı Şeyh Mucibur Rahman 23-24 Şubat'ta Pakistan'da gerçekleşen “İslam İş birliği Teşkilatı’nın Zirvesine katılmıştır. Böylece Bangladeş, Pakistan ve diğer Müslüman ülkeler ile ilişkilerini başlatmıştır. OIC’nin üyeliği çerçevesinde Bangladeş çok önemli çalışmalar imza atmıştır. Bangladeş birkaç sefer OIC Genel Sekreter Yardımcılığı görevini yapmıştır (Rashid, 2015b: 172).

1977 yılında Libya ve Mısır arasındaki siyasi anlaşmazlığını durdurarak Müslüman ülkeler arasındaki kardeşlik ilişkilerini yeniden canlandırmak amacıyla Bangladeş'in önerdiği teklifi OIC Dışişleri Bakanları toplantısının açılışında sunulmuştur ve üye ülkeler tarafından kabul görülmüştür. Aynı toplantıda nitelikli Müslüman gençlerin yetiştirilmesi için 'Teknik ve Mesleki Eğitim Merkezi' teklifi de olumlu karşılanmış ve bir sonraki Senegal toplantısında kabul olmuştur. Bangladeş Senegal toplantısında BM Güvenlik Konseyi daimî olmayan üye adaylı̆ğına OIC ülkelerin desteğini kazanmıştır. OIC İslam Barış Komitesi üyesi olarak Irakİran savaşının durdurulması için Bangladeş önemli rol oynamıştır. Bangladeş hem NAM'de hem de BM'de savaşın durdurulması için teklifler sunmuştur. Bangladeş'in bu çalışmalarında dolayı OIC'nin diğer Komiteler savaşın barışçı çözümüne gereken çalışmaları için Bangladeş Cumhurbaşkanı Ziyaur Rahman'ı tek heyeti olarak Irak ve İran'a göndermiştir. Ziyaur Rahman 1981 yılının 12 Mayıs tarihinde Bağdat'ta Irak Cumhurbaşkanı Saddam Hüseyin ile ve 13 Mayıs tarihinde Tahranda İran Cumhurbaşkanı Bani Sadr ile görüşmüş ve iki lideri savaşın durdurulması için üç ayrı komitesinin kurulmasına ikna etmiştir (Huq, 1993: 266268). Bangladeş OIC Dışişleri Bakanlarının 11. toplantısında ülkelerin siyasi ilişkilerin güçlendirmesi ve güvenliğinin korunması için Dışişleri Bakanlarıyla 'Daimî Siyasi Komitesi' 
kurulmasına teklif etmiştir. Bangladeş özellikle Müslüman ülkelerin siyasi gelişmelerin takibi için böyle bir komitenin çok önemli olduğunu vurgulamıştır (Huq, 1993: 274-276).

\subsection{SAARC’in Kurucu Ülkesi}

Dünya nüfusunun \%20'sini ev sahipliği yapan Güney Asya ülkeleri sömürgeci ülkesi Birleşik Krallığının işgal altından 1947-48 yıllarında bağımsızlığını kazanmıştır. Ancak, Keşmir sorundan dolayı bölgenin büyük güçleri olan Hindistan ve Pakistan arasında 1948, 1965 ve 1971 yılında üç savaş olmuştur. İki ülke arasındaki bu çatışma durumundan dolayı Güney Asya bölgesinde güvensizliği artmıştır (Rashid, 2015b: 159). Bu gergin atmosferi kırarak ve bölgesel düzeyde ekonomik ve siyasi iş birliğini güçlendirmek için, Bangladeş Güney Asya ülkelerin bir organizasyonu önerilen ve kurulmasında önderlik eden ülkesi olmuştur. İlk olarak 1977 yılında dönemin Bangladeş Cumhurbaşkanı Ziaur Rahman Güney Asya'da ASEAN gibi bir kurumun olmasının gereğini gündeme getirmiştir. 1977 yılının aralık ayında Hindistan'a ziyarette bulunan Ziaur Rahman Hindistan Başbakanı Morarji Desai ile bölgesel iş birliği ilgili görüşmeler yapmıştır.

Bangladeş Cumhurbaşkanı Zia bölgesel iş birliği fakrını 1979 yılındaki Commonwealth Zirvesi ve NAM Zirvesine katılan Güney Asyalı liderleriyle paylaşmıştır. Ziaur Rahman 1977-80 yılları arasında Nepal, Sri Lanka ve Pakistan ziyareti sirasında da Güney Asya liderleriyle yapılan ikili görüşmelerde bölgesel iş birliğinin önemini dile getirmiştir ve iş birliği için Nepal, Sri Lanka ve Pakistan'ın desteği kazanmıştır. Ayrıca, 1980 ilk aylarında Hindistan'a çok stratejik bir ziyarete bulunan Ziaur Rahman Hindistan Başbakanı İndira Gandhi'ye ortak çıkarları için bir bölgesel iş birliği teşkilatının önemini anlatmıştır (Khan, 2012: 35-37). Aynı yılın 2 Mayıs tarihinde Ziaur Rahman Güney Asya bölgesel iş birliği ile ilgili ilk somut teklifini ortaya koymuş (Hossain, 2010: 134) ve bir bölgesel iş birliği teşkilatının kurulması ve liderlerin bir toplantı yapılması teklifiyle Güney Asya ülkelere özel elçi göndermiştir.

Ziaur Rahman teklifinde farklı bölgelerinde çeşitli iş birliği teşkilatının kurulması ve ekonomik, toplumsal ve kültürel alanlarında ortak çıkarları sağlanmasının altına çizerek Güney Asyalı ülkelerin bu konuda başarısız olduğunu kaydetmiştir. Ayrıca, Ziaur Rahman, kurulacağı teşkilatında ikili siyasi sorunlarını konuşulmayacağını belirterek ekonomik, toplumsal, kültürel ve bilim alanlarında iş birliği olabileceğini teklif etmiştir (Khan ve Guhathakurta, 2012). Bangladeş Dışişleri Bakanlığı Güney Asya İş birliği Teşkilatı'nın ortak 
çalışma alanları ve teşkilatlanma süreçlerini nasıl izleyeceği ile ilgi detaylı bir dosyayı diğer 6 ülkeye göndermiştir. Bangladeş'in hazırladığı teklif dosyasında gelecek yıllarında kurulacak olan iş birliği teşkilatının hedefleri, hedefe ulaşma yöntemleri, çalışma şekilleri, teşkilat yapısı ve çalışma alanlarını detaylı yazılmıştır. Bu dosyada kurulacağı teşkilatının ortak alan olarak telekomünikasyon, meteoroloji, ulaşım, deniz yolu nakliyesi, turizm, tarım ve kırsal sektör, ortak girişim, seçkin ürünlerin pazar tanıtımı, bilim ve teknoloji, eğitim ve teknik ile kültürel iş birliği alanlarını önerilmiştir. Ayrıca, herhangi bir kararı için oy birliği sistemini önerilmiştir. İlgili bürokratların veya bakanların anlaşamadığı yerlerde Devlet Başkanların ortak karar sitemi, Liderlerin Zirvesi ve Dışişleri Bakanların daimî konseyin kurulması önerilerini eklemişstir (Khan ve Guhathakurta, 2012: 37). 1981 yılının 21-23 tarihleri arasında Sri Lanka'da Güney Asyalı 7 ülke Dışişleri Bakanlığı Sekreterler bir araya gelerek iş birliği ile ilgili teknik toplantıları yapmıştır. Toplantıda Bangladeş’in sunduğu dosya üzerinden tartışmalar yapılmış ve bazı kararlar alınmıştır. Ülkeler aşağıdaki kararları onaylamıştır:

i) Oy birliği ile kararlar alınacaktır.

ii) tarım, kırsal kalkınma, meteoroloji, telekomünikasyon, sağlık ve nüfus ile ilgili çalışma grubu oluşturulacaktır.

iii) Gruplar konular üzerinde detaylı çalışmalar yapacak ve bir sonraki Dışişleri Bakanlığı Sekreterlerin toplantısında önerilerini sunacaktır.

iv) Diğer iş birliği alanlarını belirlemek ve önermek için üst düzey yetkililerin bir komitesi oluşturulacaktır.

1981-1983 yılları arasında Dışişleri Bakanlığı Sekreterleri dört farklı toplantıda bir araya gelmiştir. 1-2 Ağustos 1983 yılında ise Dişişleri Bakanlar bir araya gelip "İ̧ş birliği Bildirisi”ne imzalamış ve teşkilatın amaçları ve prensiplerini belirlemiştir (Khan ve Guhathakurta, 2012). 1984 yılında resmi düzeyde bir taslak tüzük hazırlanmıştır. Tüzüğünde ülkelerin ikili sorunları ve ticari işleri hariç tarım, sağlık ve insan çalışmaları, ulaşım, posta hizmetleri, spor, kırsal kalkınma, meteoroloji, telekomünikasyon, bilim ve teknoloji, kültür ve sanat alanlarını iş birliği alanları olarak belirlemiştir (Hossain, 2010: 160; Rashid, 2015b: 134). 1985 yılııın aralık ayında Dakka'da Güney Asya Bölgesel İş birliği Örgütü (SAARC) kurulmuştur. Güney Asyalı 7 ülke devlet ve hükümet başkanlarının Dakka zirvesine bir araya gelmesiyle Bangladeş'in eski Cumhurbaşkanı Ziaur Rahman'ın çabaları gerçekleşmiş olmuştur. Dakka zirvesinde ülke devlet ve hükümet başkanların onayladığı 'Dakka Bildiri' Güney Asya ülkelerin çok önemli konulara şöyle değmiştir: "Ülkelerin devlet ve/ veya 
hükümet başkanları kabul eder ki, Dünya nüfusunun beşte bir ile oluşan Güney Asya ülkeler sömürüldüğünden dolayı yokluk, az gelişmiş, düşük üretim, işsizlik ve nüfus çoğalma gibi sorunlar ile karşı karşıya gelmiştir. Bu sorunlarını aşarak kendi halkı ve ülke için etkili bölgesel iş birliği çalışmaları büyük bir potansiyel olarak değerlendirmiştir” (Rashid, 2015b: $160)$.

SAARC, ekonomik büyüme, toplumsal ve kültürel gelişme yoluyla Güney Asyalıların yaşam kalitesini yükseltmek ve refahı teşviki ana hedefi olarak belirlemiştir (Hossain, 2010: 134). Kuruluşundan bugüne kadar SAARC birçok ortak konu üzerinde çalışmalar yapmıştır. Özellikle tarım ve ormancılık, sağlık, nüfus ve çocukların refahı, çevre ve meteoroloji, kırsal gelişim, iletişim, ulaşım, turizm, bilim ve teknoloji, eğitim, spor ve kültür, kadın hakları, uyuşturucu kaçakçılığı önleme alanında önemli çalışmalar yapmıştır. Ülkeler 1995 yılında 'Tercihli Ticaret Anlaşması' imzalamış ve 2005 bu anlaşmayı 'Serbest Ticaret Bölgesi’ olarak değiştirmiştir (Rashid, 2015b: 162-63). SAARC üyesi ülkeler enerji konusunda da çalışmalar sürdürmektedir. 'SAARC Elektrik Şebeke' projesi üzerinde ülkeler olumlu yaklaşımlar göstermişlerdir.

\subsection{SAGQ’in Kuruluşundaki Rolü}

90’lı yıllarında Güney Asya'da toplumsa ve ekonomik iş birliği çalışmaları önem kazanmış ve ülkeler büyük ilgi göstermiştir. 1996 yllında Bangladeş, Butan, Hindistan ve Nepal (BBIN) dışişleri bakanları tarafından başlatılan ve 1997 yılında Maldivler'deki SAARC Zirvesi'ne onaylanan Güney Asya Büyüme Dörtgeni (SAGQ) kurulmuştur. SAGQ kurulmasında Bangladeş'in aktif çalışmaları çok önemli rol oynamıştır. Bangladeş Dışişleri Bakanı Abdus Samad Azad 1996 yılında Yeni Delhi'de yapılan SAARC Dışişleri Bakanların toplantısında SAGQ'in teklifini masaya taşımıştır. Bu teklifine Hindistan tarafından desteklenmesi ve Nepal ve Butan'ın olumlu karşılamasıyla SAGQ kurulması çalışmaları başlatılmıştır. Kurumun konsept dosyası ve yaklaşım dosyası hazırlaması görevi Bangladeş ve Nepal bürokratlarına verilmiştir. Hindistan ve Butan ise tema dosyasını ve ortak iş birliği alanları belirlemiştir (Afroze, 2002: 203). Çevre, enerji, enerji ticareti ve yatırım, ulaşım ve turizmi çalışma alanları olarak belirleyen SAGQ Güney Asya alt bölgesel iş birliği teşkilatında Bangladeş, Butan, Nepal ile Hindistan'ın Kuzeydoğu bölgesi ve Batı Bengal bölgesi yer almıştır. Bu teşkilatı ana hedefleri olarak ülkelerin büyük politika dönüşümü yapılmadan bölgenin sosyal ekonomik büyümeyi arttırmak; büyük ekonomik iş birliği geliştirmek için 
elverişli bir ortam yaratmak; altyapı kısıtlamalarının üstesinden gelmek; politika çerçevesi ve proje uygulamasında iş birliğini kolaylaştırmasını belirlemiştir (Aric.adb.org, t.y.).

Bölgesel projelerin gerçekleştirmesinde SAARC' in yavaşlı̆̆ ve Hindistan-Pakistan arasında devam eden anlaşmazlığı dolaysıyla SAGQ'in alt bölgesel teşkilatı olarak üye ülkeleri için büyük bir ticari merkezi olabilme imkânı öngörülmektedir (Hossain, 2010: 143). Özellikle, denize kıyısı olmayan Nepal ve Butan'ın ticari işleri için Hindistan'ın Kalküta limanı çok önemli bir yer iken Hindistan'ın Kuzeydoğu bölgeleriyle Hindistan'ın ticari işler ve ulaşımı için Bangladeş önemli bir konumun olarak yer almaktadır. Öte yandan, Nepal ve Butan'a ticareti için Hindistan topraklarını kullanması Bangladeş’i çok büyük imkânları sağlayabilecektir. Ayrıca, üye ülkeler iş birliği çalışmalarıyla enerji paylaşım ve satış yoluyla bölgedeki insanları elektrik ulaştırma ve üretimi hızlandırma imkânları yakalayabileceklerdir (Mohammad, 2010: 42-43).

\subsection{BIMSTEC'in Kuruluşu ve Bangladeş}

1997 y1lında Bangladeş Bengal Körfezi Çok Sektörlü Teknik ve Ekonomik İş birliği Girişimi (BIMSTEC)'in kuruluş üyesi olmuştur. 1994 yllında Tayland'ın önderliğinde Bangladeş, Hindistan, Sri Lanka ve Tayland'ın kurduğu BIST-EC ekonomik iş birliği teşkilatı daha sonra Nepal, Butan ve Myanmar'ın katılımıyla BIMSTEC adıyla çalışmaları başlatmıştır. Bengal Körfezi kıyılarında yer alan ülkeler bir araya gelerek bir alt bölgesel teşkilatı olarak ortak ticari çalışmaları yürüterek SAARC ve ASEAN arasında bir köprü oluşturma amacında kurulan BIMSTEC kuruluş döneminde ticari, teknoloji, ulaşım ve enerji gibi 13 alanında iş birliği çalışmalarını arttırmaya kararlaşmıştır. Daha sonra bölgede artırmakta olan terör sorunlara karşı mücadeleyi de önemli bir alan olarak belirlemiş̧lerdir. Bu kuruluş aslında Bangladeş ve Hindistan'ın 'Doğuya Bak' politikasının en önemli ürünü olarak Güney Doğu Asya ile Güney Asya'nın ticari iş birliğinin yolunu açmıştır.

\subsection{D-8 ve Bangladeş}

Türkiye Başbakanı Necmettin Erbakan'ın önderliğinde kurulan gelişen Müslüman ülkenin teşkilatı Gelişmekte Olan Sekiz Ülke D-8'in önemli bir üyesidir Bangladeş. Müslüman ülkeler arasında teknolojik ve ekonomik kalkınma düzeyleri, ticari potansiyelleri ve nüfusları itibariyle önde gelen ülkeler ile güçlü bir ekonomik ve ticari iş birliği kurulmasına yönelik 
Türkiye'nin teklifini kabul ederek D-8 kuruluş çalışmalarında Bangladeş önemli yer almıştır (Mfa.gov.tr, t.y.).

\subsection{APTA'da Bangladeş}

Ülkelerin kalkınmaya yönelik alt bölgesel faaliyetler, ticaret ve yatırım, ulaştırma ve turizm, çevre ve sürdürülebilir kalkınma çalışmaları için kurulan Birleşmiş Milletler Asya ve Pasifik Ekonomik ve Sosyal Komisyonu (UNESCAP) kapsamında 1975 yılında Asya’nın gelişmekte olan ülkeler ile Bangkok Anlaşması kurulmuştur. UNESCAP'in gelişmekte olan üye ülkeler arasındaki ticaret müzakerelerine ilişkin bu ilk anlaşma ilk olarak çok üyeli Tercihli Ticaret Anlaşması (PTA)'na imzalanan 5 ülkeler arasında Bangladeş de yer almıştır. 2005 yılında Asya ve Pasifik Ticari Anlaşması (APTA) olarak değiştirilen bu anlaşmanın diğer üyeleri ise Hindistan, Lao Halk Demokratik Cumhuriyeti, Kore Cumhuriyeti, Sri Lanka ve Çin'dir. Bu anlaşma Doğu ve Güney Asya'yı birleştiği gibi dünyadaki en kalabalık iki ülke Çin ve Hindistan için de ortak bir kurum olmuştur (Iyer, t.y.). 1975 kuruluşundan 2001'e kadar üye ülkeleri arasındaki ticaret düşük kalmıştır ve bu anlaşmadan sonra kurulan bölgedeki birçok kuruluşlar teklif edilen imtiyazlar, oluşturulan üye içi ticaret miktarı ve ortak çıkarları bakımından üstesinden gelmiştir. Ancak, 2001 yılında Çin'in katılması APTA'yı bölgede daha aktif ve dinamik bir anlaşmaya dönüştürmüştür. Dünya'nın en kalabalık bölgesi olan Asya' da, ülkeler arsında iş birliği yoluyla ortak ticari ve ekonomik kalkınmaya hedeflenen Bangladeş APTA kuruluşunda önemli rol oynadığı gibi hâlihazırda da aktif çalışmalar sürdürmektedir.

\subsection{SASEC ve Bangladeş}

2001 yılında kurulan Güney Asya Alt Bölgesel Ekonomik İş birliği (SASEC)'ın kurucu üyesidir Bangladeş. Ulaştırma, ticari kolaylaştırma, enerji ve ekonomik koridor geliştirme çalışmalarıyla bölgesel refahı teşvik etmeyi, ekonomik firsatları geliştirmeyi amaçlayan proje tabanlı bir ortaklık teşkilatıdır. Bangladeş, Butan, Hindistan, Maldivler, Myanmar, Nepal ve Sri Lanka ile oluşan SASEC Güney ve Güney Doğu Asya'da ticaret ve iş birliğini ilerletmeye ve Çin Halk Cumhuriyeti ve küresel pazara bağlantı ve ticaret geliştirilmeye hedeflemektedir. Bölgesel ticaretini kolaylaştırmak için SASEC, çoklu sınır ötesi ulaşım ağlarını güçlendirmekte ve zamanı hızlandıran ve sınır ötesi malların, araçların ve insanların taşınması maliyetlerini azaltan modern ve etkili gümrük idaresinin kurulmasına destek olmaktadır. 
SASEC ayrıca, üye ülkelere enerji güvenliğini geliştirme konusunda altyapı geliştirme desteği sağlamaktadır. Bölgede enerji ticaretini teşvik ederek maliyetleri ve ithalat bağımlılığını azaltmasında da yardımcı olmaktadır (SASEC, t.y.).

\subsection{BCIM-EC’nin Kuruluşu}

Bangladeş, Çin, Hindistan, Myanmar BCIM alt bölgesindeki ekonomik faaliyetleri artırmak için çok modlu taşımacılık ağı fikri 1990'larda, Bangladeşli Profesörü Rehman Sobhan tarafından önerilmiştir (Yesmin, 2019). Rehman çok modlu taşımacılık bağlantısı ve altyapının hazırlamasının, işlem maliyetlerini önemli ölçüde azaltabileceğini, ticareti ve yatırımı teşvik edebileceğini ve sonuç olarak bölgedeki ülkelerin büyük ölçüde faydalanabileceği savunmuştur (Rahman, 2014). Daha sonra BCIM'in sivil toplum kuruluşların başlattıkları çalışmaları sonucunda BCIM Forum gündeme gelmiştir. Dört ülkenin STK'ların 1999 yılında başlattığı 'Kunming Girişimi' adlı 'Uluslararası Bölgesel Ekonomik İş birliği ve Kalkınma Konferansı'nın ortaya koyduğu bölgesel ortak ticareti ve ulaşımına yönelik önerileri üzerinde 2004 yılında ülkelerin Dışişleri Bakanlarının bir araya getirmiş ve BCIM İş birliği çalışmalar başlamıştır. Daha sonra Çin Başbakanı Li Keqiang, Mayıs 2013'te Hindistan ziyareti sırasında BCIM alt bölgesindeki ekonomik koridor fikrini önermiş ve Çin-Hindistan'ın ortak açıklama sonrasında BCIM-EC'nin kurulmasını resmen başlamışıtr. Bangladeş ve Myanmar da alt bölge genelinde ekonomik koridorun gelişmesine karşı güçlü ve olumlu tepki vermiştir. Önerilen BCIM ekonomik koridoru, BCIM ülkelerinin 20 büyük kentini birbirine bağlayan $2.800 \mathrm{~km}$ 'lik bir ekonomik koridor inşa etmeyi amaçlamaktadır. İpek Yolu'nun modern versiyonu olarak tanımlayan BCIM Ekonomik Koridörü bu dört ülkeyi karayolları, demiryolları, deniz yolları ve hava yolları ile bağlayacak bir bölgesel ekonomik çalışmasıdır (Hossain, 2010: 147). Bu ekonomik koridoru gerçekleştiğinde insanların ve malların sınır ötesi akışını kolaylaştıracak, ticaret engellerini en aza indirecek, ülkelere bölge pazara erişim sağlayacak ve çok taraflı ticareti artıracaktır.

\section{Sonuç}

Eleştirel jeopolitik kavramının ortaya koyduğu özellikleri çerçevesinde Bangladeş'in kuruluşundan 2006 yılına kadarki dış politika çalışmalarına bakıldığında, Bangladeş'in hem uluslararası alanında kendi konumunu almayı ve ekonomik hedeflerini elde etmeye çalıştı̆ını ve önemli ilerleme kaydettiğini görmek mümkündür. Özellikle Hindistan'ın etkisi altından 
başarıyla çıkarak $\mathrm{ABD}$, Çin, Batılı ülkeler ve Müslüman ülkeleriyle ilişkileri kurduğu ve uluslararası kuruluşlarında girişimci rolü oynayarak çok kısa bir süre içinde kendi coğrafi ve ekonomik zorlukları aştı̆ı görülmüştür. Bangladeş aynı zamanda uluslararası ve bölgesel iş birlik çalışmalarında yer alarak komşu ülkeleriyle ikili meselelerinde de çözümler üretmiştir. Bağımsızlık sonrasında aktif dış politika sonucunda Bangladeş, Müslüman ülkeleriyle kardeşlik ilişkileri geliştirerek Ortadoğu ülkelerinde vasıflı ve vasıfsız iş̧̧ilerine iş imkânı sağlamış ve devamlı olarak büyük bir ekonomik kazanç elde etmeye başarmıştır. Aynı zamanda, Çin ile ekonomik, ticari ve askeri alanında yakın iş birliği kurarak ve sürdürerek kendi ekonomik ve alt yapı geliştirmesini hızlandırdığı gibi askeri alanında da güçlenmiştir. BM ve BM Barış Gücü’ne aktif katılım sağlayarak dünya kuruluşları ve büyük ülkelerden ekonomik ve alt yapı konusunda büyük destekler almaya başarmıştır. Özellikle BM Barış Gücü çerçevesinde gittikleri ülkelerde kendi kültürünü temsil ederek Bangladeş, ticari imkanlarını açmış ve yumuşak gücü ektisini bırakmıştır.

\section{Kaynakça:}

Afroze, S. (Ed.). (2002). Regional cooperation in South Asia: New Dimensions and Perspectives. Bangladesh Institute of International and Strategic Studies.

Ahamed, E. (Ed.). (2004). Foreign Policy of Bangladesh: A Small States Imperative. Kamol Kuri Prokashon. https://www.abebooks.co.uk/Foreign-Policy-Bangladesh-SmallStates-Imperative/755761025/bd

Aric.adb.org. (n.d.). South Asia Growth Quadrangle (SAGQ) Initiative. Aric.Adb.Org. Erişim: 6/7/2019, https://aric.adb.org/initiative/south-asia-growth-quadrangle

Bdnews24.com. (2013, Ekim 31). Bangladesh elected ECOSOC member. Bdnews24.Com. Erişim: 12/8/2020, https://bdnews24.com/bangladesh/2013/10/31/bangladesh-electedecosoc-member

Dalby, S. (1991). Critical Geopolitics: Discourse, Difference, and Dissent. Environment and Planning D: Society and Space, 9, 261-283.

Hossain, D. (2010). Globalization and New Regionalism in South Asia: Issues and Dynamics (1st Edition). A H Development Publishing House.

Hossain, U. (2014). United Nations Organization. In Banglapedia (Online). Asiatic Society of Bangladesh. http://en.banglapedia.org/index.php?title=United_Nations_Organization 
Huq, M. S. (1993). Bangladesh in International Politics: The Dilemmas of the Weak States. The University Press Limited.

Iyer, H. (n.d.). IV. The Bangkok Agreement: Prospects for Trade Expansion in the AsiaPacific Region (Bulletin on Asia-Pacific Perspectives 2003/04 No. 2003/04). unescap.

Khan, Z. R. (2012). Ideology and Internal Dynamics of South Asian Regional Cooperation. Içinde Z. R. Khan \& M. Guhathakurta (Eds.), Regional Cooperation and Globalisation: Bangladesh, South Asia and Beyond (1st ed., pp. 31-58). The University Press Limited.

Khan, Z. R., \& Guhathakurta, M. (Eds.). (2012). Regional Cooperation and Globalisation: Bangladesh, South Asia and Beyond (1st ed.). The University Press Limited.

Kuus, M. (2010). Critical Geopolitics. İçinde Oxford Research Encyclopedia of International Studies. Oxford University Press. https://oxfordre.com/view/10.1093/acrefore/9780190846626.001.0001/acrefore9780190846626-e-137

Mfa.gov.tr. (n.d.). Gelişen Sekiz Ülke (D-8). T.C. D1şişleri Bakanlığı. Erişim: 3/10/2020, http://www.mfa.gov.tr/gelisen-sekiz-ulke-_d-8_.tr.mfa

Mohammad, G. (Ed.). (2010). National security Bangladesh, 2009. The University Press Limited in association with Bangladesh Institute of International and Strategic Studies.

Momen, N. (2004). Bangladesh at the Security Council: The Arab-Israeli Issue. Iç̧inde E. Ahamed (Ed.), Foreign Policy of Bangladesh: A Small States Imperative (pp. 125142). Kamol Kuri Prokashon. https://www.abebooks.co.uk/Foreign-PolicyBangladesh-Small-States-Imperative/755761025/bd

Peacekeeping.un.org. (n.d.). United Nations Peacekeeping. United Nations Peacekeeping. Erişim: 21/7/2020, https://peacekeeping.un.org/en/node

Rabbi, A. R. (2017, Ekim 24). Bangladesh in peacekeeping-Challenges, Tragedies and Achievements. Dhaka Tribune. 15/6/2020 https://www.dhakatribune.com/world/2017/10/24/heroes-challenges-tragediesachievements/

Rahman, M. (2014, Mart 15). BCIM-economic corridor: An Emerging Opportunity. The Daily Star. Erişim: 16/7/2020 https://www.thedailystar.net/bcim-economic-corridoran-emerging-opportunity-15533

Rashid, H. ur. (2015). International Relations and Bangladesh. The University Press Limited. 


\section{ISSN 2717-7262 ISPEC Journal of Social Sciences \& Humanities}

SASEC. (n.d.). SASEC on the Move. SASEC. Erişim: 12/5/2019, https://www.sasec.asia/index.php?page=sasec-on-the-move

Tuathail, G. Ó. (1996). Critical Geopolitics: The Politics of Writing Global Space. University of Minnesota Press.

Tuathail, G. Ó. (1999). Understanding Critical Geopolitics: Geopolitics and Risk Security. İçinde C. S. Gray \& G. R. Sloan (Eds.), Geopolitics, Geography and Strategy (1st Edition, pp. 107-124). Frank Cass Publishers. http://public.eblib.com/choice/publicfullrecord.aspx?p=1596750

Yeşiltaş, M. (2016). Jeopolitik. İçinde Ş. Kardaş, A. Balcı, \& N. Tenekeci (Eds.), Uluslararası İlişkilere Giriş: Tarih, Teori, Kavram ve Konular (pp. 351-365). Küre Yayınları.

Yesmin, S. (2019, Şubat 17). Tapping the potential of BCIM-EC. Financial Express. Erişim: 26/10/2019 https://thefinancialexpress.com.bd/views/views/tapping-the-potential-ofbcim-ec-1550415602 